\title{
1. Constrained experimentalism and the World Bank
}

\subsection{INTRODUCTION}

With an annual budget that dwarfs the outflows coming from even the largest of bilateral donors, ${ }^{1}$ the World Bank is widely regarded as the most potent actor in the global development business. The Bank's operational reach has through its history expanded substantially, and now covers areas as disparate as education and healthcare, judicial reform, macroeconomic policy, mining, and transportation. This breadth of reach serves to enhance the popular vision of the Bank as a supra-national colossus, capable of using its control over finance to shape a wide array of global practices.

Amongst the voluminous literature on the World Bank, prominent contributions have homed in on a particular structural tension at the heart of the organisation. Put simply, it has been suggested that it is extremely difficult for the organisation to function simultaneously as a bank and as a development agency. ${ }^{2}$ As a bank, the organisation is required to seek out lending opportunities that are capable of generating predictable and large revenue streams, to allow its borrowers to ultimately make repayments on contracted loans. As a development agency, the organisation is required to orient its activities toward the needs of the global poor. A structural tension emerges from the fact that this constituency group - the global poor - unfortunately provides limited opportunities for the generation of large and stable resource flows. In walking this tightrope, so the critics say, the World Bank seems to systematically tilt towards bank-like activities, to the detriment of development agency-like concerns.

This book focuses on the World Bank's lending for housing. Lending for housing can be seen as a particular manifestation of this general bankversus-development agency structural tension. By creating a portfolio dominated by mortgage market expansion, the organisation has reproduced the oft-criticised practice of privileging its 'big end of town' bank-like operations. In this sector, lower-income groups are typically unable to access the formal networks of housing finance that are increasingly being supported by the World Bank's housing operations. Given that these 
lower-income groups tend to have the most pressing need for improved housing, the organisation's bank-like concerns can be seen to be trumping its development agency-like concerns in this operational sphere.

Through the book as a whole, I unpack the dynamics that have led to this preponderance of bank-like behaviour in World Bank lending for housing. Overall, I suggest that a process of constrained experimentalism has shaped the evolution of operational practice. Staff were conscious of stepping into the operational unknown when commencing lending for housing in the early 1970s, and processes of trial-and-error-based experimental learning were used to guide operational reform. Through the decades, this experimentalism has underpinned a series of operational shifts that have pushed the organisation from a more development agency-like to a more bank-like approach. From an early focus on directly improving the lowestquality housing within borrowing countries, World Bank engagements first moved toward reforming national housing agencies and enhancing their capacity to deliver housing finance to lower-income groups, before most recently coming to focus on mortgage market expansion.

Although driven by an underlying experimentalism, this movement from a development agency-like approach to a more bank-like approach has been constrained by notable internal and external factors. Inside the Bank, shifting personnel bases have served to limit the range of activities undertaken within its housing sector operations. In particular, the loss of urban planning expertise through the 1990s contributed to a significant narrowing of its sectoral focus. Dynamics outside the Bank also shaped the operationalisation of lending for housing. Resources have gravitated towards borrowers whose commitment to complementary policy agendas has been previously demonstrated. Through the 1970s and into the 1980s, Bank staff and borrowers shared a vision of state agencies as providing a foundation stone on which national housing systems could be built. Through the 1990s and 2000s, the state was replaced by market-based actors and processes at the heart of Bank staff's and borrowers' visions of national housing systems. Shifts in lending for housing involved the elision of, on the one side, the Bank's trial-and-error-based learning and, on the other side, domestic preferences and political economy structures.

The suggestion that changes in the World Bank's lending for housing have been driven by a process of constrained experimentalism provides an intervention in existing literature on the politics of change in international organisations. Beyond this core contribution from the book, two additional engagements are offered with existing literatures across Politics and International Studies.

The detail presented on shifting operational practice at the Bank allows for debates over the nature of the (post-)Washington Consensus to be 
engaged with. While existing literatures suggest that a focus on 'getting the institutions right' to support market exchange constitutes a novel component of the post-Washington Consensus period, in World Bank lending for housing the focus dates back to its earliest interventions. I also suggest that the purported 'pro-poor' focus of the post-Washington Consensus is, in fact, not reflected in this operational area. In lending for housing, over time targeting has moved from low-income groups towards those on more moderate income levels. Beyond this engagement with literature on the post-Washington Consensus, the detail presented on transformations in national housing systems allows for debates over the emergence of regulatory state structures in the global South to be engaged with. In this regard, I suggest that, while national housing systems have indeed moved from hierarchical 'provider state' modes toward more networked and market-based 'regulatory state' modes, the distributional impact has not matched the progressive potential suggested by some literature on the regulatory state of the global South.

The primary purpose of this opening chapter is to locate the strands of engagement with literatures on the politics of operational change at the World Bank, the rise of the regulatory state of the South, and the (post-) Washington Consensus. In the following three sections of this chapter, I sketch out these interventions in turn. Further detail on these three core contributions is added through the subsequent, more empirically focused, chapters, which are framed in relation to these themes. Through the penultimate section of this chapter, I provide a commentary on the approach to studying the World Bank that underpins this work, before concluding the chapter with an overview of the book's remaining content.

\subsection{THE POLITICS OF OPERATIONAL CHANGE IN INTERNATIONAL ORGANISATIONS}

Within Political Science and International Studies literature, a sustained focus on the role of international organisations (IOs) has been maintained throughout the last three decades. In the paragraphs below, I briefly outline the contours of this evolving body of work, before bringing together the IO literature with emerging work on experimental governance. In suggesting that shifting practices at the Bank can usefully be characterised as a manifestation of constrained experimentalism, I reinforce the message from recent IO work that significant operational changes take place beyond the radar of materially powerful states, and extend related efforts to clarify the interplay between actors and institutional processes that shape these outcomes. 
The roots of contemporary IO scholarship can be traced to literature on regime theory. The works brought together by Stephen Krasner (1982) are widely acknowledged to have provided the intellectual foundations for this line of scholarship, which sought to explore the causes of international regime formation, and the consequences of their operation. A relatively broad definition was adopted to guide these seminal works, with attention directed toward the 'principles, norms, rules, and decisionmaking procedures around which actor expectations converge in a given issue area' (Krasner 1982: 185). These debates about the impact and evolution of institutional structures were often infused with reflections on hegemonic decline, with particular interest directed toward the question of whether and how regimes could maintain peace and an open international economic order in the face of waning US power (see Keohane 1986; Grieco 1988; Mearsheimer 1994).

The issue of institutional design grew to become a significant focus of these and later regime theorists. Factors including the distribution of voting power within a given institutional setting, control over the admission of new members, and ability to shape mandate and operational agenda were highlighted as key mediating factors involved in translating states' preferences and capabilities into outcomes (Koremenos et al. 2001). More recent contributions have developed this body of work by adding principal-agent (PA) modelling to the analytic toolkit available to those studying international organisations (Hawkins et al. 2006). These applications have often highlighted the difficulties faced by state representatives when trying to exercise control over their IO agents. ${ }^{3}$ PA-inspired literature has readily acknowledged that a 'zone of discretion' exists, within which IO staff and senior management can draw on their expertise to craft solutions to complex problems of global public policy (Thatcher and Stone Sweet 2002). While PA studies have tended not to delve into these lower-order interactions, a parallel literature has sought to shine a light on this form of below-the-radar politics of international organisations.

The work of Emanuel Adler and Peter Haas (1992) helped to catalyse the emergence of more 'everyday' analyses of international organisations. In a call to extend the analytic focus of early regime theory work, Adler and Haas argued that students of international politics needed to concentrate on exploring the 'inner world' through which ideas and interests were brought into being. For Adler and Haas, international institutions helped to provide the foundational understandings of aspects of global politics on which discussions, decisions, and, ultimately, actions were founded. While state representatives undoubtedly played a privileged role in these decision-making processes, a heterogeneous range of actors in and around 
IOs were able to exert significant influence through their capacity to shape intersubjective understandings.

Extending Adler and Haas's call, Ernst and Peter Haas (1995) turned attention to the role played by institutionalised learning as a tool to allow IOs to navigate the complexity of global public policy. For Haas and Haas (1995: 259), learning was defined as a 'political process whereby "consensual knowledge" is applied by policymakers to change their policy projects'. Groups of like-minded professionals, or 'epistemic communities', were identified as playing a particularly important role in framing the conventional wisdom in a given policy sphere. Through Adler, Haas, and Haas, then, a sustained focus was placed on the broad range of actors whose input can shape outcomes in international organisations.

Attention on the processes through which ideas, expertise, and practices interact and evolve within international institutions has remained high since these early interventions. Michael Barnett and Martha Finnemore's (2004) exploration of international organisations in global politics provides perhaps the most prominent contribution to this line of scholarship. Building from Haas and Haas's focus on learning, Barnett and Finnemore identify expertise as a centrepiece of IO power. By attaining the status of 'expert authority', an IO can for Barnett and Finnemore become able to frame the way in which policy problems and solutions are perceived by a wide range of relevant actors.

Amongst more recent IO literature, the topic of epistemic communities, expertise, and operational change has continued to feature in prominent contributions. Jeffrey Chwieroth (2010a), for example, has demonstrated that staff's educational background played a central role in shaping the International Monetary Fund's (IMF) approach to capital account liberalisation. In subsequent work by Ban (2015), we see - again in relation to the IMF - that senior management have proactively used their control over appointments and promotions to build support for expansionary fiscal policy in the post-Global Financial Crisis period. The process of new staff carrying ideas into the organisation and up the chain of command can, it seems, be an explicitly political one.

A broader collection of scholarship presents thematically similar explorations of the politics of expertise and operational change in IOs, but does so without directly framing cases in terms of education and learning. Using a variety of terms, works have sought to probe the ways in which bodies of knowledge and associated practices have been contested and reformed across a range of policy spheres and institutional settings (e.g. Momani 2004; Nielson et al. 2006; Weaver and Park 2007; Weaver 2008; Broome 2009, 2010b; Clegg 2010; Momani 2010; Park 2010; Vetterlein 2010; Moschella 2011; Broome and Seabrooke 2012; 
Clegg 2012; Moschella and Tsingou 2013; Clegg 2014b; Gallagher 2014; Moschella 2014; Vetterlein and Moschella 2014). Valuable insights have been generated that have helped to clarify both the detail of historic and contemporary operational practices, and the bureaucratic dynamics that underpin these practices. In these cases, change has often been catalysed by entrepreneurial individuals incrementally promoting a particular policy agenda, and using their control over institutional structures to roll out new practices. ${ }^{4}$

Through this work, by shedding light on the institutional dynamics that have shaped changing ideas and practices at the World Bank, I hook into the line of IO scholarship whose genealogy runs through Adler, Haas, and works mentioned above. By suggesting that agent-level contingency (specifically, the shrinking of the urban planning team at the World Bank) contributed to the path of operational change, I reiterate a common message from these literatures. By suggesting that the process of operational change in World Bank lending for housing can be usefully characterised as constrained experimentalism, I loop back to the focus of Haas and Haas on learning in international institutions. With Bank staff using ongoing project-level reviews and periodic sectoral reviews to guide changes to practice, institutionalised learning can be seen to be a significant driver of operational change. Given the existence of this institutionalised learning and a significant degree of flexibility on the means and ends of policy interventions, these dynamics can be seen to fall under the rubric of experimental governance.

The literature on experimental governance is most closely associated with European Union Studies, and in particular with the work of Charles Sabel and Jonathan Zeitlin (e.g. Sabel and Zeitlin 2008, 2010, 2012). Sabel and Zeitlin employ the term 'experimentalism' to refer specifically to the mode of governance the drives advances at the heart of the European Union (EU). Reviewing EU Studies literature, Sabel and Zeitlin (2010: 1-28) highlight a scholarly consensus over the existence of deliberative discussion within the regional organisation's institutional structures; through reasoned exchanges of ideas, actors' initial preferences can be transformed. In addition, a broad-based agreement is flagged up relating to the importance of socialisation processes. In this connection, deliberative preference updating is most prevalent where civil servants, experts, and interest groups identify with a particular epistemic community. In the language of EU Studies, deliberative decision making can be seen to occur most readily where actors have been socialised into a comitology system. Complementing and extending these existing lines of analysis, Sabel and Zeitlin in particular focus attention on what they term the experimentalist 'architecture of decision-making' in the EU (2010: 2). 
In elucidating this architecture of decision making, Sabel and Zeitlin identify four defining characteristics of the European Union's experimentalism. First, overarching policy goals and measures for gauging their achievement are set through joint action by member states and EU institutions. Second, in line with the principle of subsidiarity, lower-level units are provided with autonomy to design and adjust, on a countryby-country basis, the means through which to meet overarching policy goals. Third, implementing units are required to report on performance in a manner that allows for comparative insights to be generated. Fourth, the overarching policy goals and measures for gauging achievement are periodically reviewed and may be subject to amendment.

The work of Sabel and Zeitlin remains focused on the relationship between learning and operational change in the European Union. ${ }^{5}$ In the short amount of time that has passed since the publication of their seminal works, attempts have been made to explore the utility of the concept of experimental governance in capturing the nature of interactions across other institutional settings. In this regard, de Burca et al. (2013) have suggested that an emergent mode of 'global experimentalist governance' can be discerned within contemporary international politics. ${ }^{6}$ Focusing on private networks of global governance, Brassett et al. (2012) too find evidence of nascent experimentalism in trans-border settings. Focusing on global financial governance, Campbell-Verduyn and Porter (2014) identify what might be termed experimental ecologies. Overall, Campbell-Verduyn and Porter (2014: 409) note a trend toward increasingly prominent experimentalism across a range of institutional settings.

Through this work, I extend this emergent literature on experimentalism in global governance in two directions. First, I suggest that operational change in World Bank lending for housing can be usefully characterised as being driven by experimentalism, and specifically by a mode of experimentalism that contributes to a non-incremental form of operational change. Second, I suggest that, in this case, experimental governance has failed to generate the beneficial outcomes that are commonly associated with the technique. In fact, a series of internal and external constraints has seen this experimentalist dynamic leading to a drift away from the Bank's developmental mission in its lending for housing operations.

In making this first claim that experimentalism can be detected at the World Bank, I draw upon the conceptualisation of experimental governance offered by Campbell-Verduyn and Porter. Campbell-Verduyn and Porter follow Sabel and Zeitlin's lead in incorporating into their definition of experimentalism factors including the retention by lower-order actors of the ability to set and adjust policy goals and measures, the use of systematic reporting and periodic review to shape these efforts, and the 
reliance on cross-national study as a means of generating evidence of best practice. However, whereas Sabel and Zeitlin highlight the use of comparison between cases exhibiting simultaneous variation as a core feature of learning in the EU, Campbell-Verduyn and Porter (2014: 411) suggest that experimentalism 'may occur with the evaluation of a succession of harmonised implementation efforts'. The World Bank's experimentalism has, by and large, followed this diachronic mode of evaluation. This mode of evaluation has contributed to the progression of the Bank's housing operations through a series of discrete frameworks. The repeated trajectory of operational change has seen a relatively homogeneous framework being rolled out to borrowers, individual evaluations of project implementation leading to a systematic review of operational practice, and the systematic review then catalysing the emergence of a new - and relatively homogeneous - framework.

The second extension comes with the challenge I present to the functionalist hue that is often attached to analyses of experimentalist governance. Proponents of experimental governance have presented the mode as a catalyst of improved institutional performance; national spaces provide laboratories from which trial-and-error-based learning identifies best practices and best-fit designs. ${ }^{7}$ One challenge to this vision of experimentalism as technocratic efficiency has been presented by Fossum (2012), who suggests that Sabel and Zeitlin's elevation of bureaucratic actors in fact serves to undercut space for democratic representation within governance processes. I develop a different line of critique, suggesting that the efficacy of experimentalism at the Bank has been constrained by a range of internal and external factors.

Inside the Bank, the organisation's trial-and-error-based approach to operational change has been constrained in particular by its shifting staff base. After the Bank entered the sphere of housing policy in the 1970s, efforts were made to bolster its urban planning expertise. A small team with specialist knowledge on the intersection between housing policy and development remained in the Bank through to the mid-1990s; however, personnel changes around this time saw a dissipation of this expertise, with the institutional centre of gravity moving toward financial sector development. The message that (changing) staff composition impacts on institutional practice is well established in IO studies literature; here, I suggest that this factor has shaped the operationalisation of the Bank's trial-and-error-based learning. Overall, with this constraint, World Bank housing operations gravitated away from projects designed to improve the housing of low-income populations, and towards a mode that intersected through mortgage market expansion - with the housing needs of those on more moderate and higher income levels. 
Outside the Bank, the flow of the Bank's experimentalism has been constrained by shifting political economy structures and preferences amongst its borrowers. In general, the Bank's lending for housing has been delivered into national contexts in which prior commitment to supportive reform has been demonstrated. In the more recent phases of lending for housing, this dynamic has seen the Bank's market-based (and often financial sector-targeted) projects being channelled to borrowers with sympathetic agendas. Again, the message that (changing) borrower preferences impacts on IO practice is well established in existing literature; here, I suggest that this factor has shaped the operationalisation of the Bank's experimentalism. This external constraint has reinforced the direction of travel in World Bank lending for housing toward more market-based projects - projects that, overall, have included a lower level of targeting towards low-income populations than their predecessors.

In Chapters 2 to 5 , detail is added to this characterisation of the evolution of World Bank lending for housing as a case of constrained experimentalism. In the two sections below I sketch out the contributions made by this study to literatures on the rise of the regulatory state of the global South, and on the (post-)Washington Consensus.

\subsection{REGULATORY STATES IN THE GLOBAL SOUTH}

In seeking to offer a holistic exploration of the World Bank's changing approach to lending for housing, through this book I bring together an analysis of World Bank- and borrowing country-level dynamics. As outlined above, the headline message from the work relates to the characterisation of the interplay between these dynamics as a case of constrained experimentalism: a message that speaks particularly to literature on the politics of operational change in IOs. The study also provides a foundation from which to engage with literature on the rise of the regulatory state, and specifically as applied to the state transformation in the global South.

Transformations in national housing systems promoted by the Bank broadly cohere with visions of the rise of the regulatory state. However, in the move from 'positive' to 'regulatory' state practices in this area, the needs of lower-income groups have often been sidelined. While existing literature on the rise of the regulatory state in the South remains limited, insights from this study highlight the challenges involved in channelling the benefits from market-based processes to groups with low levels of market access or influence. In the paragraphs below, I outline the contours of literature on the rise of the regulatory state and related studies of housing 
system transformation, before outlining the intervention offered through this study.

A prominent strand of literature on the regulatory state is anchored to Giandomenico Majone's analysis of transformations in Western European political economies that occurred from the late 1970s. Prior to this point, the post-Second World War period is characterised by Majone as a time in which Western European states prioritised the expansion of 'discretionary macroeconomic management' within their policy agendas. According to Majone (1997: 141), through this era: '[A]ny evidence of market failure was deemed sufficient to justify state intervention, often in the intrusive form of centralised capital allocation and the nationalisation of key sectors of the economy. Indeed, centralisation and unfettered policy discretion came to be regarded as prerequisites of effective governance.' The outcome of this logic was, for Majone, the construction of the positive state.

The movement away from the activist and centralised state is explained as being driven by the confluence of many factors. Majone suggests that increased trade and financial linkages across borders served to limit the extent of governments' capacity to tax and spend. In addition, growing dissatisfaction with the perceived inefficiencies within state-led production processes and the tendency for enterprises to be captured by political elites and trade unions served to generate momentum for change. In Majone's (1997: 142) words, 'an increasing number of voters were ... willing to support a new model of governance that included privatisation of many parts of the public sector ... [and] more competition throughout the economy'. The reformed mode of governance was labelled regulatory in view of the emergent mechanisms of state control, through which 'public utilities and other industries deemed to affect the public interest are left in private hands, but are subject to rules developed and enforced by specialised agencies' (Majone 1997: 144).

Beyond Majone, complementary lines of analysis have suggested that this move toward regulatory modes has involved increasing levels of complexity in governance processes. As states move away from being monopoly providers within hierarchical structures, mechanisms of service delivery emerge that bring together a more heterogeneous range of actors (see Osborne and Gaebler 1992; Osborne 1993; Dunleavy and Hood 1994; Barlow and Röber 1996; Frederickson 1996; Moran 2002). David LeviFaur $(2005,2013)$ has suggested that the depth of transformation has been such that a reformed mode of regulatory capitalism is in the process of being brought into existence across the globe. While the distributional consequences of the rise of regulatory state structures have attracted relatively little comment, it has been suggested that social goals can effectively be layered into more network-oriented regimes (Haber 2011). 
Many analyses have sought to expand understanding of the rise of the regulatory state by exploring specific manifestations in detail. Transformations in sectors ranging from education (King 2007) to policing (White 2010) to transportation (Lodge 2003) have been subjected to close analysis across a range of national contexts. The intersection between housing and the rise of the regulatory state, too, has been the focus of several studies. Lisa Alexander (2009) has shown that stakeholder engagement has been difficult to achieve in US public housing reform, thereby problematising the view that regulatory modes improve governance effectiveness by harnessing insights from a heterogeneous range of actors. Other works have critically reviewed the attempts made to use national, regional, and local governance structures to nudge social rental tenants toward being 'autonomous and accountable consumers' (McKee 2008), and to engage in education, training, and employment (Flint 2004). Schwartz and Seabrooke's (2009) comparative study tells a story of enduring differences in what they label 'varieties of residential capitalism', emphasising the complexity of the institutional constellations that shape the balance between patterns of private ownership, private rental, and social rental.

Recently, attempts have emerged to use studies of state transformation in the global South to extend literature on the rise of the regulatory state. Brief reflections on the topic were offered in early literature on the regulatory state, with suggestions being made that changing modes of governance outside of advanced industrialised states were likely to be particularly influenced by external factors (e.g. Dolowitz and Marsh 2000). Relatedly, several analyses suggested that the policies and practices of institutions of global economic governance were serving to tether states in the global South to increasingly marketised and regulatory modes of governance (e.g. Wade 2003; DiCaprio and Gallagher 2006). Focusing on Latin America, Jordana and Levi-Faur (2005) demonstrate that, in line with the pattern of change observed in Western Europe by Majone, through the 1980 s and 1990 s there was a proliferation in the creation of independent regulatory agencies. Similar findings have been presented in relation to transformations across Asia (Ginsburg and Chen 2008).

Amongst the country case studies presented, a repeated finding has been that the creation of regulatory state structures can serve to enhance the efficiency of service delivery in developing-country contexts. While acknowledging that moves away from positive structures of governance can present opportunities for corruption and patronage, Cook and Mosedale (2007: 3-4) emphasise that 'better regulation and competition play an important part in improving both the performance of enterprises and the delivery of essential services, and ... are integrally related to a pro-poor 
development process'. Elsewhere, Dubash and Morgan (2013) present a balanced assessment of the distributional politics that follow from the rise of the regulatory state of the South. For Dubash and Morgan (2013: 10) the marketisation of service provision can lead to the poorest being priced out of service provision, with poorly functioning agencies 'allocating costs . . . across social classes ill-equipped to bear them'. However, Dubash and Morgan (2013: 11) suggest that, on balance, 'micropolitics' is what matters; regulatory states provide 'hollow shells' that are 'fleshed out' through the interactions across international, national, and local networks in a given context.

Turning to the sectoral focus of this study, relatively few attempts have been made to explore the intersection between housing and the rise of the regulatory state of the South. In a systematic review of Latin American experiences, Bouillon (2012) highlights the importance of regulatory agencies effectively protecting creditor rights and managing land registries as foundations of effective national housing system performance. Chiquier and Lea (2009) deliver a similar message within their broad-based review of developing-country experiences. Focusing on Cambodia, Biddulph's (2014) work highlights the importance of domestic politics in shaping distributional outcomes across nascent regulatory structures. In Cambodia, efforts to create an effective land registry were co-opted by national elites to facilitate a process of land capture. The difficulties of ensuring that the benefits from the regulatory governance of housing become widely dispersed are also noted in analyses from Mints (2000), Zhang (2000), Butner et al. (2004), Burell (2006), and Chen and Deng (2014) of housing finance innovation in a range of developing and emerging market contexts. More optimistically, Serra (2003) and Durand-Lasserve and Royston (2012) foreground the potential gains to lower-income groups that can be generated through effective land registration.

Overall, this study serves to affirm that patterns of transformation in the realm of housing provision have followed the broad contours outlined by literatures on the rise of the regulatory state. Through the 1970s and 1980s, the dominant thrust of World Bank lending for housing was targeted at enhancing the performance of positive state structures. Here, state agencies typically played a direct role in both housing construction and the provision of housing finance. Through the 1990s and 2000s, the dominant thrust of World Bank lending moved toward supporting the establishment of regulatory state structures. Projects were designed to catalyse private construction and the provision of private financing to support housing purchases, while also seeking to bolster state capacity to regulate property rights.

In addition to providing this affirmation that transformations in national 
housing systems mirrored broader shifts from positive to regulatory state structures, through this study I demonstrate that these changes have typically promoted operations that have benefited those on moderate and higher incomes. While some support was provided in World Bank loans to allow state agencies to facilitate lower-income groups' access to housing finance, ordinarily through the 1990s and 2000s such mechanisms were not included. The observed patterns of housing system transformation fit with the reflections offered by Dubash and Morgan (2013) on the regulatory state of the South, demonstrating the difficulties of ensuring that increasingly market-based systems cater to the needs of low-income groups.

This sketch of the contribution being made through this work to literatures on the rise of the regulatory state of the South is substantiated through Chapters 3 to 5 in particular, where reviews of national housing system transformations are provided. In the following section of this chapter, I outline the third of the points of academic engagement that follow from the study, relating namely to debates over the Washington Consensus and the post-Washington Consensus.

\subsection{THE (POST-)WASHINGTON CONSENSUS}

The terms 'Washington Consensus' and 'post-Washington Consensus' are intimately associated with the World Bank and its 'Bretton Woods twin', the International Monetary Fund. Across the field of Development Studies, the labels have been used to pick out points of continuity and change in the policy paradigms promoted by the Bank and Fund from the 1980s onwards. Through the paragraphs below, I engage primarily with ongoing efforts to map the degree of congruence between rhetoric associated with the (post-)Washington Consensus and the content of the Bank's operational practice. I suggest that core prescriptions associated with the Washington Consensus did indeed rise to prominence in the Bank's lending for housing through the 1980s, with deregulation of housing construction and liberalisation of the financial sector becoming mainstays in this period. In contrast, Bank practice since the late 1990s has not reflected central elements of the post-Washington Consensus. In particular, in the organisation's lending for housing, a focus on institution building pre-dates the post-Washington Consensus, and the purported enhancement of pro-poor targeting has not materialised. These findings illustrate the potential value of using detailed sectoral analysis to extend discussions over the nature of the (post-)Washington Consensus. After first providing an outline of debates over the (post-)Washington Consensus, I 
then present the insights gathered from the analysis of World Bank lending for housing projects.

When exploring the Washington Consensus, it is useful to begin by considering the context from which the approach emerged. The Washington Consensus can be seen as a reaction against the dominance in the 1970s of the idea that, for states across the global South, stateled import substitution industrialisation represented the most effective pathway to economic development. In the words of John Williamson (1990), who in the early 1990s introduced and popularised the term, '[t]he Washington Consensus said that this era was over'. Williamson coined the term in an attempt to capture the new orthodoxy he saw being championed by policy elites in Washington, an orthodoxy whose dominance had been secured through the course of the 1980s.

In outlining the core content of the Washington Consensus, Williamson (1993: 1332-1333) identified the principal reforms that had risen to the status of accepted wisdom. These reforms included the attainment of balanced government budgets, a prioritisation of productivity-enhancing public expenditure in areas such as education, health, and infrastructure, the creation of a broad tax base to 'sharpen incentives without lowering realised progressivity', liberalisation of the financial sector, trade liberalisation, privatisation, and deregulation to facilitate the entry of new firms into markets. Williamson (1993: 1333) is explicit in noting that the content of the Washington Consensus should be viewed as a universal intellectual convergence, a paradigm shift that was rooted in the 'body of robust empirical generalisations that forms the core of economics'.

While for Williamson the Washington Consensus represented a vision of technocratic best practice, for critical observers the paradigm came to represent a mistaken and potentially damaging prescription. The occasion of the 50th anniversary of the foundation of the World Bank and IMF, a milestone reached in 1994, served as a touchstone for the emergence of a series of challenging evaluations. Analyses were produced presenting claims of systematic underperformance in countries with Washington Consensus-like policy suites, and suggesting that state-led development had proven to be effective in others. In relation to the former, the comparative underperformance across Latin America since the 1980s was presented as a case in point; in relation to the latter, the economic transformations achieved by the 'Asian tigers' and at an earlier stage by Japan were singled out (see Cavanagh et al. 1994; Danaher 1994; Chossudovsky 1997).

In addition to these critical evaluations of the real-world impact of Washington Consensus-type policies, Williamson's claims over the depth of scholarly agreement on the fundamentals of the Washington Consensus were also subjected to contestation. Moises Naim (2000: 506), for 
example, attempted to challenge the level of 'consensus' in the Washington Consensus, claiming that 'an objective assessment . . . shows that confusion rather than consensus characterised then and now the intellectual climate among experts in the field of economic development and market reforms'. Extending this line of critique, Sarah Babb (2013) later argued that the Washington Consensus, far from representing the apogee of development best practice, should be understood as a policy paradigm produced by transnational political and social forces and legitimised through economics scholarship.

Amongst the many interventions made into debates over the Washington Consensus, the most prominent came from a former chief economist of the World Bank, Joseph Stiglitz. Indeed, Stiglitz's interventions helped shift the terms of debate away from the Washington Consensus and toward the post-Washington Consensus. In accomplishing this transformation, Stiglitz moved to hook into the broad-based discontent with the Washington Consensus, and to ally this popular mood with innovations that he had introduced into the field of economics through previous decades.

By the 1980s, the neo-classical approach had come to sit at the mainstream of the discipline of economics. Stiglitz's core academic contributions centred on his refinement of assumptions that lay at the heart of this approach. Working with Andrew Weiss, Stiglitz took aim at the neo-classical claim that markets, with the aid of perfect information, tended toward equilibrium. In their analysis of credit markets, Stiglitz and Weiss (1981) posited that information imperfections could lead to persistent imbalances of supply and demand over the long run. Through analyses that also focused on insurance and labour markets, Stiglitz's central message came to be that information gaps and asymmetries present potent obstacles to the achievement of effective, competitive markets. Mechanisms for ameliorating and overcoming these limiting conditions included contractual design and incentives at the firm level, and a commitment to increased openness and transparency at the level of governments (Snowdon and Stiglitz 2001; Runde 2002). ${ }^{8}$ From the late 1990 s onwards, Stiglitz began to reframe these academic insights into an attempt to outline a call for a move toward a post-Washington Consensus.

By virtue of its profile and directness, the attack launched by Stiglitz on the Washington Consensus and his advocacy for a post-Washington Consensus constituted a headline-grabbing intervention. In addition to condemning specific pieces of policy guidance provided within IMF loan arrangements in the late 1990s (Stiglitz 1998), Stiglitz (2001: 41) questioned the appropriateness of the overarching Washington Consensus framework: 
If there is a consensus today about what strategies are most likely to promote the development of the poorest countries of the world, it is this: there is no consensus except that the Washington Consensus did not provide the answer ... To most people, the Washington Consensus represents a set of policies predicated in a strong faith - stronger than warranted either by economic theory or historical experience - in unfettered markets and minimising the role of government.

In outlining his call for a revised approach to development theory and practice Stiglitz drew on insights from his information-theoretic approach to economics, heralding the need for more attention to be placed on the positive role to be played by governments in creating and maintaining market-supporting institutional structures. While anchored to a need to facilitate information flows, the post-Washington Consensus as outlined by Stiglitz (2001) seemed to hint at countries being given room to experiment with a broad range of development policies, providing that these state interventions were complementary to market mechanisms.

The impact of Stiglitz's interventions was impressive in the scale and pace of responses that followed. In the evaluation of Ben Fine (2001: 17), the 'complete absence of disagreement with Stiglitz' approach to economic theory or policy ... [was] remarkable'. The language of the post-Washington Consensus rapidly gained traction inside the World Bank itself. Perhaps most notably, the World Bank (2005f) report on Economic Growth in the 1990s presented a distancing of the organisation from the Washington Consensus. Within its reflections on the 'unexpected' results that had followed the adoption of Washington Consensus-type policies, the Bank report affirmed that 'there is no unique universal set of rules ... [for] sustained growth' (2005f: xiii). The take-home message from the study (2005f: xiii-xiv) was that, in the post-Washington Consensus world, development should be understood as a complex and contingent task, requiring an accumulation of human and physical capital, efficient allocation of resources, and a sharing of the benefits of growth. The Bank's policy priorities were to be based on country-specific diagnostics, with success being dependent on a willingness to learn from experimentation.

Beyond Stiglitz and the World Bank, the post-Washington Consensus has attracted a high degree of commentary and remains a heavily contested term. On one side, relatively supportive voices have sought to translate the abstract calls for changed practice into more detailed operational templates (e.g. Cohen 2001; Rodrik 2006). On the other, more critical views have been presented over perceived blind spots and shortcomings. In this regard, a continued subordination of the state to the market (e.g. Fine 2001; Bonal 2002, 2004), and the relative neglect of policies to support the expansion of production-oriented infrastructure (Hayami 
2003) have in particular been identified. Discussion has also come to focus on the relationship between the post-Washington Consensus and the development strategies pursued by a range of emerging market economies, including most notably China (see Huang 2010; Kennedy 2010; Ban and Blyth 2013).

Given that the framework is intimately associated with a rejection of the Washington Consensus's narrow field of vision, it is perhaps unsurprising that it is difficult to identify core features of the post-Washington Consensus. However, two features have become prominent signifiers of the approach, used to mark the post-Washington Consensus out from its predecessor. These post-Washington Consensus innovations are, namely, a focus on institution building, and on pro-poor targeting within contemporary development practice.

The former innovation is closely related to Stiglitz's contributions noted above, relating to the supportive conditions required to enable markets to deliver efficient outcomes. The move toward 'getting the institutions right' is widely acclaimed as a hallmark of the postWashington Consensus. Emphasis is often placed on the creation of structures to regulate the financial system, to deter excessive risk taking by banks while also providing reassurance to banks and their depositors. However, the mantra that state-supported institutions are important for the effective functioning of markets is held to be an established component of the post-Washington Consensus (e.g. Ahrens 2002: 368-378; Onis and Senses 2005: 274-275; Rodrik 2006: 976-977). The latter intervention is related to an acknowledgement that the Washington Consensus was ill equipped to deliver sufficiently progressive patterns of growth. The World Bank and, to a more limited extent, IMF moved to mainstream poverty reduction as an operational goal from the late 1990s (Clegg 2010, 2014a). A commitment to the inclusion of propoor targeting, in particular within interventions focused on education, health, and the creation of a 'safety net' welfare programme, has come to be a widely held pillar of the post-Washington Consensus (e.g. Fine 2001: 2-3; Ruckert 2006: 34-36).

Much of the debate over the nature of the (post-)Washington Consensus has taken place at a relatively high level of abstraction, with pronouncements from the Bank and prominent development economists commonly being used as the means to gain analytic traction of the subject. In contrast, a small number of works have sought to explore the detail of the World Bank and IMF's operational practice as a point of entry. Both Fine (2001: 16), when asking whether the post-Washington Consensus simply provides rhetorical gloss on unchanging policies, and Broome (2015), when challenging scholars to shed light on the detail of Bank and Fund practice 
rather than simply assuming a high degree of correspondence between operational output and the dominant paradigm, present support for such a move. The analyses of Sumner (2006) and Broome (2015) provide examples of the insights that can be generated from such an approach. Sumner's study suggested that, by the early 2000s, core Washington Consensus policies had begun to 'go missing' from World Bank- and IMFsupported reform programmes. Broome's study, which took a long view of IMF policy advice from the 1980 s to the 2010 s, similarly suggests that lower recourse to liberalisation- and privatisation-related content can be observed within the post-Washington Consensus era.

Through this study, I contribute to these efforts to explore the correspondence between World Bank practice and the precepts of the (post-)Washington Consensus. The foundations of this engagement are drawn from a systematic analysis of the content of the Bank's housing sector projects. To generate insights into this topic, I have coded all projects signed off between 1972 and 2012 according to the presence or absence of four core pieces of policy content. The first two pieces of content relate to deregulation, and to financial liberalisation; ${ }^{9}$ these focuses represent the components of the Washington Consensus that are of greatest relevance to the study of housing system transformations, with observations shedding light on to the extent to which pro-market orthodoxy prevailed in Bank practice through the 1980s and 1990s. The second two relate to institution building and pro-poor targeting; ${ }^{10}$ these focuses represent widely accepted foundations of the post-Washington Consensus, with observations shedding light on to the extent of operational shifts through the post-2000 period.

An overview of the percentage of housing sector loans containing provisions relating to deregulation of housing construction, financial liberalisation, institution building, and pro-poor targeting is provided in Figure 1.1. Taking the 1983-2002 period to mark the time during which Washington Consensus prescriptions rose to the fore, a relatively high degree of correspondence can be seen between Bank practice and relevant entries on Williamson's (1993) checklist of principal reforms. Through the first decade of World Bank lending for housing, projects aimed at strengthening the capacity of state agencies to directly provide new and improved housing. Thus, from 1972 to 1982, there was very little focus on either the deregulation of construction to encourage the entry of private firms or the liberalisation of the financial sector to encourage the increased provision of private housing credit. From 1983 to 1992, a step-change in operational practice occurred.

During the first decade of the Bank's housing lending, only around 5 per cent of housing loans aimed to promote deregulation and the entry 


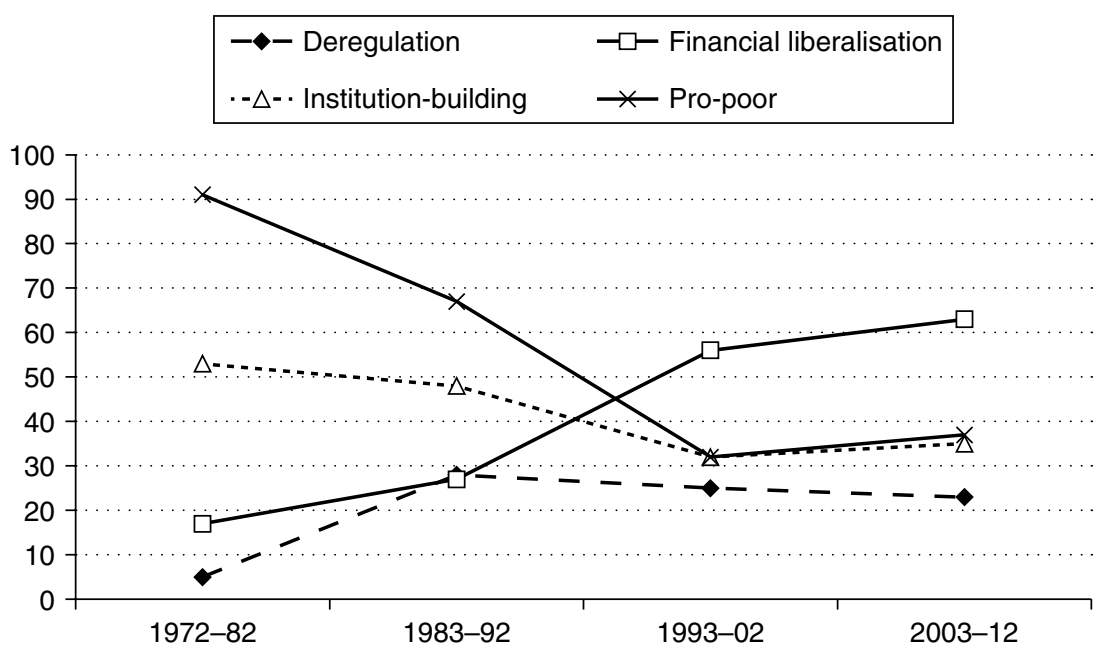

Figure 1.1 Lending for housing and the (post-) Washington Consensus

of private firms into the realm of housing provision. Moves to involve private provision gained substantial traction from 1983 to 1992, when around one in three projects included this goal. Project documentation typically was high on rhetoric, but low on detail. Often, ambitious commitments to develop self-sustaining, market-based housing systems were outlined, and accompanied by statements that private providers would be contracted in, with little or no reflection on mechanisms to promote and support such activities. ${ }^{11}$ From 1992 to 2002, the proportion of projects with a focus on supporting the entry and expansion of private provision within national housing systems remained relatively stable. Increasingly, these stipulations were featured in arrangements made with post-socialist transition states through this time. Overall, then, the Washington Consensus period aligned with a clear move toward deregulation and the promotion of private construction firms into national housing systems.

In relation to the liberalisation of housing finance, there was also a strong correspondence between Bank practice and Washington Consensus precepts through the 1980s and 1990s. Through this time, World Bank priorities in housing operations coalesced around mortgage market expansion. A focus on promoting private housing credit had existed within Bank operations from the start of its sectoral operations. From 1972 to 1982, 11 projects included provisions aimed at expanding the depth of the national mortgage market. The bulk of these interventions were, however, 
very limited in scale, typically providing investment funds to only one preexisting lender.

From 1983 to 1992, as the Washington Consensus was enjoying its rise to dominance, the focus on financial liberalisation in Bank lending for housing became more deeply embedded. Through this time, around 30 per cent of projects aimed to increase the provision of housing credit by private actors. Amongst these World Bank arrangements, state agencies were often used as intermediaries from which private lenders could access credit tranches. ${ }^{12}$ In later projects, auctions and other competitive mechanisms were incorporated into this mediation of resources to private lenders, to allow for the setting of market-based rates of interest. Additional mechanisms used to promote the flow of private credit included the introduction of new modes of mortgage lending, involving flexible rates and lengthened repayment terms. ${ }^{13}$

The focus on the creation of increasingly market-based housing finance systems was consolidated through the latter phase of the Washington Consensus in the decade from 1993. Whether focusing on Latin America or post-socialist transition countries, through this period many interventions were focused on the transformation of statecontrolled finance networks. With the dawning of the post-Washington Consensus, this prioritisation of mortgage market expansion was, from 2003 to 2012, even further consolidated. Around 60 per cent of projects were targeted toward achieving this aim through this most recent period. In addition, a notable focusing on the creation and expansion of mortgage liquidity facilities was embedded in this time. From 1972 to 1982 , just US $\$ 28$ million was provided by the Bank for this purpose; ${ }^{14}$ this volume rose to US\$260 million through the 1983-92 period, ${ }^{15}$ before leaping to US\$700 million in $1993-2002,{ }^{16}$ and US\$850 million in 2003-12. ${ }^{17}$ This consolidated focus on mortgage market expansion is the core driver of the reduction in pro-poor targeting in the Bank's lending for housing. In the paragraphs below I first explore the relatively low level of pro-poor targeting during the post-Washington Consensus era, before closing by reviewing trajectories relating to institution building in World Bank loans.

Through the first decade of its operations in the area, pro-poor targeting was an almost ubiquitous feature of World Bank lending for housing. Typically, through this time targeting was achieved on the basis of housing need, rather than through income-based metrics. ${ }^{18}$ Projects that included plans for the upgrading of existing settlements were focused on the districts with the poorest standards of shelter and supporting infrastructure. Newbuild operations were planned with relatively low specifications, typically providing small plots of land with basic utility connections to enable them 
to be affordable by lower-income groups. With Bank operations focusing largely on upgrading existing settlements and providing low-specification new-build housing, from 1972-82 around 90 per cent of projects included mechanisms to achieve pro-poor targeting.

Through the course of the 1980s, the centre of gravity in the World Bank's housing operations shifted away from upgrading informal settlements and serviced plot provision, and towards reforming housing finance systems. In this period, the majority of World Bank finance was mediated through state agencies, which on-lent in order to allow for improved housing to be accessed. With the inclusion in project documentation of eligibility criteria for these schemes, recipients' income came to feature more prominently as a mechanism for targeting resources. Pro-poor targeting continued to feature in most Bank interventions through this decade. However, with around two-thirds of all projects featuring such targeting, the rate declined notably when compared to the previous decade. ${ }^{19}$

Pro-poor targeting in the Bank's housing arrangements underwent a further reduction in the 1993-2012 period. This time, the centre of gravity in Bank lending for housing moved from state- to market-based housing finance systems. Only a handful of arrangements that focused on this modality included mechanisms for channelling resources toward lower-income groups. ${ }^{20}$ An additional driver of this reduction in pro-poor targeting came in the nature of support provided to housing agencies in post-socialist countries. Across these cases, projects concentrated on the complexities of moving away from state-dominated systems, and focused on supporting the creation of private construction and finance rather than on distributional concerns. ${ }^{21}$ In spite of the discursive commitment to pro-poor development that accompanied the increasing prominence of the post-Washington Consensus at the Bank, the proportion of lending for housing that included pro-poor targeting mechanisms remained stable through the 2003-12 period, at a level notably below that achieved in preceding decades.

Alongside the pro-poor turn, institution building is presented as a key feature of the post-Washington Consensus. However, in its housing sector lending, a focus on building the institutional structures needed to support market exchange has featured throughout the history of Bank operations. Indeed, the prominence of this focus declined notably from the first years of Bank lending in this area.

From 1972 to 1982, the primary focus of World Bank lending for housing was increasing state agencies' capacity to provide upgraded housing. Within this period, over 50 per cent of projects featured conditions relating to the strengthening of property rights registration systems. Typically, these components involved rolling out cadastral mapping of 
land-ownership boundaries, and improving the accompanying titling systems. The introduction and extension of these institutional structures provided necessary foundations for formal market-based exchange, ${ }^{22}$ and were presented also as enhancing individuals' willingness to invest in housing improvements. The level of attention on property mapping and registration systems remained broadly stable across 1983-92. During this time, just under half of Bank projects included provisions to strengthen the institutional structures through which home-ownership rights were recorded and protected.

According to conventional wisdom, the Washington Consensus began its transition into the post-Washington Consensus at the turn of the millennium. At this time, the World Bank's approach to institution building underwent a significant transformation, while also actually decreasing in quantitative prominence. As mortgage market expansion was consolidated as the central goal of the Bank's lending for housing, an additional dimension to institutional strengthening emerged; to enhance financial institutions' willingness to lend, a new focus was placed on mechanisms to protect creditor rights. Alongside land mapping and property registration systems, a focus on judicial foreclosure processes began to feature within project documentation. This shift aligned closely with the Stiglitz-inspired view of the post-Washington Consensus, which focused in particular on building institutional structures to encourage efficient and effective financial market operations. However, in quantitative terms, this agenda remained somewhat marginal at the Bank. From 2003 to 2012 only around one-third of projects included a focus on building market-supporting institutional structures. Accordingly, the focus on institution building remained broadly static from the Washington Consensus to the postWashington Consensus period.

By mapping the content of World Bank practices against signal features of the (post-)Washington Consensus, two core messages emerge. First, the content of lending for housing through the 1980s and 1990s aligned closely with Washington Consensus prescriptions, specifically those relating to financial liberalisation and deregulation. Second, the content of operations from the early 2000s has matched less well with post-Washington Consensus prescriptions. The extent of both pro-poor targeting and institution building in recent years remained on a par with levels through the Washington Consensus period, and notably below the levels that featured in earlier phases of lending for housing. These findings demonstrate the benefit of using analyses of project content to shed light on the nature of the (post-)Washington Consensus, and reiterate the message from Fine (2001), Broome (2015), and Kentikelenis et al. (2016) to use such information to test prevailing opinion. 


\subsection{STUDYING WORLD BANK LENDING FOR HOUSING}

In this penultimate section of the chapter, I provide an overview of the approach taken through this study of the World Bank and the politics of housing provision. Three goals are accomplished in the paragraphs below. I first provide information about the World Bank housing project database, which constitutes a cornerstone on which the book's analysis is built. I then sketch the rationale for case-study selection, before concluding with some clarifications of key terms that shape the work.

World Bank lending for housing commenced in 1972. To shed light on the detail of Bank operations in this area, I have undertaken a systematic review of relevant World Bank project documentation. Buckley and Kalarickal's (2006) analysis provided the point of entry into the topic. ${ }^{23}$ Buckley and Kalarickal had identified and classified World Bank lending for housing from 1972 through to the early 2000s; I extended the coverage through to 2012, and reclassified according to an amended typology. ${ }^{24}$ The typology takes the form of a four-fold categorisation of World Bank housing projects, differentiating between interventions where the primary focus was on the provision of plots of land with basic utility connections for self-build ('serviced plots'), the upgrading of existing informal shelter ('upgrading'), an extension of state capacity to provide housing credit ('state-based housing finance'), or an extension of the private provision of housing credit ('market-based housing finance'). A single-count method was used when categorising projects; where multiple forms of intervention were incorporated into the same project, categorisation followed the dominant theme. An overview of this coding exercise is provided in the Appendix. By bringing together lending operations undertaken through the organisation's International Bank for Reconstruction and Development, International Development Association, and International Financial Corporation facilities, the World Bank housing project database provides a holistic overview of the organisation's operations in this area.

Beyond providing a detailed account of the ebb and flow of the World Bank's operational practice, through this book I also outline the intersection between its lending and transformations in national housing systems. Existing housing studies literatures have commonly focused on three classes of national housing system outside of advanced industrialised states. The features of the Latin American class typically involve mixed provision between three forms of housing supply. Relatively established market-based provision typically caters to the needs of higher-income populations, and state-led provision to groups of public sector and other formally employed workers. A substantial proportion of lower-income 
populations rely on the informal sector, amongst which poor-quality housing can be prevalent. ${ }^{25}$ The state socialist class is characterised by public ownership, and state-led construction and credit allocation. ${ }^{26}$ The identifying aspects of the sub-Saharan African class include a relatively low capacity on the part of state actors to intervene in national housing systems, market-based systems whose output caters to the needs of a limited section of the relatively well-off urban population, and high levels of informal provision. ${ }^{27}$ In order to foreground core properties of each system, through this study I refer to these three classes as the mixed provision model, the state socialist model, and the informal model.

The three case-study chapters within the book have been structured so as to probe the interactions between the World Bank and each of these classes of national housing system. To probe the overall form of operational engagement between the Bank and the mode, each chapter includes a review of the broad sweep of World Bank lending. From these reviews, the wide applicability of the points of analytic engagement introduced through this chapter are illustrated. It is specifically suggested that lending for housing has typically flowed to partners where a pre-existing commitment to supportive reform has been demonstrated, thereby highlighting the impact of the Bank's external environment on the process of constrained experimentalism driving changes to operational practice. It is also suggested that World Bank interventions have supported moves toward regulatory systems of housing governance across each of the three modes of housing system.

Within each of the three chapters, additional detail is provided into the relationship between the Bank and its borrowers through studies of individual country transformations. Countries have been selected on the basis of extent of World Bank involvement in housing system transformation. Amongst the whole cohort of 81 World Bank member states that have received housing sector interventions, the mean average number of loans contracted is three. Having hosted 17 World Bank projects, Mexico provides the member of the mixed provision mode of national housing system with the highest level of engagement. With five and four housing arrangements respectively, China and Tanzania feature as representatives of the state socialist and informal modes. ${ }^{28}$ Drawing on archival sources, new insights are provided into the successes and failures of the Bank's housing operations in these contexts. The three cases serve to consolidate the central messages from the book, which is that a process of constrained experimentalism has driven the World Bank's changing operational focus from supporting the development of positive to regulatory modes of housing governance, and that the benefit from Bank-supported interventions has increasingly been distributed towards those on moderate and higher incomes. ${ }^{29}$ 
Throughout this book, the term 'national housing system' is taken to refer to the formal institutional structures and processes that support the provision of shelter within a given territorial unit. These systems can include state agencies with responsibility for housing, urban development, land registration, housing finance, and mortgage market regulation, and private organisations including property developers and housing finance providers. For most individuals across developing and emerging market economies most of the time, however, housing provision in fact comes through largely informal processes. In urban spaces, house construction is often incremental in nature; a central core will be built either directly by the householder or through the grey economy, on land to which the individual has no recognised legal claim. Throughout the book, I use the terms 'informal' and 'unplanned' to refer to these settlement types. Elsewhere, terms including 'shanty town' and 'slum' are widely used to denote such developments; while these terms direct attention to the extremely poor conditions that can exist in such spaces, the more neutral language serves to avoid categorical homogenisation, and admits the possibility that decent housing can be generated through such processes.

\subsection{CHAPTER OVERVIEW}

In this first chapter, I have provided an overview of the extensions of existing literatures that are offered through the study of World Bank lending for housing. By conceptualising the process of operational change as being driven by constrained experimentalism I engage with work on the politics of change in international organisations, particularly by directing attention to the mechanics of learning in these locations. In addition, extensions have been offered to literature on the rise of regulatory state structures across the global South, and to debates over the nature of the (post-)Washington Consensus. The following chapters of the book serve to add detail and nuance to these overview accounts.

In Chapter 2, I present the analysis of institutional change at the Bank. In the years following the organisation's establishment, lending remained tightly focused on large-scale infrastructure projects capable of generating revenue flows to enable borrowing governments to meet the Bank's repayment schedules. Under the presidency of Robert McNamara the scale and scope of the institution's lending expanded dramatically, and it was through this time that the first housing sector engagements took place. In this chapter, the interactions between trial-and-errorbased experimentalism and changes in personnel in reshaping operational practice are reviewed. Overall three phases of operational practice are 
identified, with an initial phase focusing on state-led construction and upgrading, a second phase on working to promote the expansion of housing finance through state-based mechanisms, and the most recent phase prioritising mortgage market expansion.

I move on to the first of the thematically organised case studies of national housing system transformation in Chapter 3 . The mixed provision housing system is characterised by a co-existence of state intervention and an active market-based sector, with a substantial quantity of urban housing coming through informal supply. This model gained particular prominence across Latin America, and I begin the chapter by reviewing the regional transformations in which the World Bank has played a prominent role. Initially, World Bank support aimed to increase the focus on the needs of low-income groups within these state-dominated systems. With Chilean reforms through the 1980s providing a model of an alternative market-based approach, Bank interventions came from the 1990s to focus heavily on bolstering the role of private agents and reconstituting the state as a regulatory actor. The Mexican case is used to explore these trends in greater detail. As was the case in aggregate lending trends, this movement toward engaging with private housing finance has been accompanied by a reduction in pro-poor targeting.

Chapter 4 moves on to consider the state socialist model. Here, a broadbased review of transformations across the Soviet Union and its former satellites is accompanied by a detailed exploration of the Chinese case. In these instances, national housing systems in which state-led supply and state ownership predominated were consolidated though the second half of the twentieth century. Although there was substantial variation in the detail and overall performance of these housing systems, in many cases low levels of housing construction served to generate significant overcrowding. World Bank interventions have sought since the 1990s to support the transition to market-based provision, in particular by establishing legal structures and institutional mechanisms to protect private ownership, promoting private sector supply, and encouraging the entrance of private financial actors into the realm of mortgage lending. Across these cases, dramatic transformation has been achieved. However, the extent to which Bank support has been targeted according to income- or housing condition-based assessments of need has remained limited.

Chapter 5 presents the final of the case studies of housing system transformation. Focusing on the evolution of housing systems across sub-Saharan Africa, I outline the pressures on national housing systems that have been generated by rapid rates of urbanisation across the region. While during times of colonial administration the extent of urban expansion remained tightly managed, through the post-independence era 
major cities across the region have experienced rapid population growth. With limited state and private sector capacity, much new urban housing has come through informal and unplanned settlement. Over time, World Bank resources have been increasingly channelled away from intervention in these informal processes and toward market-based housing finance systems. The Tanzanian example provides a case in point, in which the recent Bank-supported creation of the Tanzania Mortgage Refinance Company has brought housing improvement to a narrow band of the country's high-income population.

In the book's final chapter, I consider a range of emerging trends in World Bank lending for housing that demonstrate potential to reinvigorate the organisation's pro-poor focus. The recent integration of a focus on housing micro-finance and on sanitation services includes significant evidence of needs-based targeting, but is likely to remain a marginal feature of the Bank's portfolio. Changed practices in the realm of water supply have increased the focus on lower-income populations' needs; this is an established operational area at the World Bank, with relatively large associated flows of resources. A confluence of internal dynamics at the Bank with borrowers' preferences and reform agendas will, however, be necessary for the potential benefits from each of these three emerging areas to be effectively realised.

\section{NOTES}

1. In 2015, for example, the Bank's total new outlays stood at some US\$45 billion (World Bank 2015e). At US\$23 billion, the total US aid budget in the same year was around half this size. See OECD Development Assistance Committee official website, available at http://www.oecd.org/dac/stats/documentupload/ODA $\% 202013 \% 20$ Tables $\% 20$ and $\% 20$ Charts\%20En.pdf (accessed 5 May 2016). Throughout the book, to aid comparability of data all US\$ amounts are presented in 2001 values.

2. This observation is most closely associated with the work of Rich (1994) and Gutner (2002), both of whom explore the bank-versus-development agency trade-off in relation to environmental protection.

3. The PA framework was initially transposed into the field of Political Science by Weingast and Moran (1983) and Weingast (1984). IO-related applications have illustrated that, even where a sufficient level of consensus exists amongst state representatives to allow a collectively sanctioned call for reform to be issued, states need to be able to monitor compliance effectively, and to make use of appropriately targeted incentives to shape staff behaviour (Gould 2006; Tierney 2008; Clegg 2014a). Recent work from Stone (2008, 2011) suggests that, in exceptional circumstances, the US in particular holds a special capacity to shape IO behaviour by pulling on informal levers. However, a broad message from PA scholarship is that state control over the particularities of reform processes is difficult to achieve.

4. Park and Vetterlein (2010) and Vetterlein and Moschella (2014) provide particularly useful reviews of the state of the art of this literature on the politics of operational change in international organisations. Both sources particularly flag the importance 
of institutional structures as important mediating factors in processes of operational change.

5. Evaluations of the utility of the concept to the study of the EU have been provided by Borzel (2012) and Nance and Cottrell (2013).

6. De Burca et al. (2013) focus specifically on the UN Convention on the Rights of Persons with Disabilities, the Montreal Protocol on the Depletion of the Ozone Layer, and the Inter-American Tropical Tuna Commission.

7. Indeed, Sabel and Zeitlin (2010: 2) suggest that the density of contemporary political economic networks necessitates experimentalism. High levels of complexity mean that it has become increasingly difficult for policy goals and means to be determined ex ante, but rather they must be discerned through reflexive practice.

8. For a comprehensive review of Stiglitz's contribution to the information-theoretic approach to economics and his intersection with debates over the Washington Consensus, see Fine (2001: 3-10).

9. A project was recorded as promoting 'deregulation' where mechanisms were included to ensure that monopoly provision by state agencies would be challenged, and that associated construction services would be provided largely or wholly by private sector providers. A project was recorded as promoting 'financial liberalisation' where mechanisms were included to increase the volume of housing finance being provided by private institutions within a national housing system, whether through own-account lending or by on-lending resources originated by third-party actors.

10. A project was recorded as promoting 'institution building' where mechanisms were included to establish or improve state and regulatory structures to support the functioning of the housing market, including for example through oversight of mortgage lending, codification and enforcement of foreclosure procedures, and cadastral surveying and property registration. A project was recorded as 'pro-poor' where mechanisms were included to target housing improvements preponderantly to individuals with belowaverage income, or to individuals living in low-quality shelter with inadequate access to basic utilities and services.

11. See, for example, World Bank (1991d: 14-15).

12. These processes were designed to function as a stepping-stone toward establishing selfsustaining market networks; the hope was that, once private lenders had been able to successfully test the water with Bank-supplied resources, future operations would be undertaken using their own asset base.

13. See, for example, World Bank (1992b).

14. This figure includes lending to Lebanon (1974), Bolivia (1976), India (1978), Senegal (1980), and Indonesia (1980).

15. This figure includes lending to India $(1985,1987)$, Côte d'Ivoire (1987), Morocco (1989), Pakistan (1990), and Poland (1992).

16. This figure includes lending to Argentina (1993, 1999), Lebanon (1996), Bangladesh (1997), Mexico (1997, 2001), Jordan (1997), West Bank (1997, 1998), Estonia (1998), Sri Lanka (1999), South Africa (1999), India (1999), Venezuela (1999), Georgia (2000), Korea (2000), the Central European Region (2002), and China (2002).

17. This figure includes lending to India (2003, 2004), China (2004), Colombia (2004), Egypt (2004, 2006, 2009), Mexico (2004, 2008), Peru (2004), Romania (2004), South Africa (2004), Latvia (2009), and Tanzania (2010).

18. Exceptions included the Tanzanian arrangement of 1974 that identified the lowestincome 16 per cent of the population as the target population, the Korean arrangement of 1981 that identified those on 25 per cent average income, and the Mexican arrangement of 1981 that identified those on 150 per cent of the minimum wage.

19. In addition to reproducing the expansive classification of pro-poor elements in upgrading and serviced plot provision, I have graded housing finance-focused interventions as pro-poor where mechanisms have been included to ensure that the majority of resources are directly channelled toward the lowest-income 50 per cent of the population or sub-sections therein. 
20. Exceptions included the Mexican arrangement of 1999 that identified the fourth to seventh income deciles as direct recipients and the Venezuelan arrangement of 1999 that targeted finance toward barrios inhabitants.

21. See, for example, arrangements approved with the governments of Albania (1994), China (1994), the Russian Federation (1995, 1996, 1997, 2001), Lithuania (1996), and Latvia (2002).

22. See Kim (2004) for an exploration of the relationship between property rights claims and housing markets.

23. A debt of gratitude is owed to Robert Buckley and Jerry Kalarickal, whose willingness to share their preparatory analysis made it possible to identify relevant projects and associated documentation. Without these materials, the study in its current form would not have been possible.

24. Buckley and Kalarickal deployed a five-part typology, classifying each housing loan as focusing on 'slum upgrading', 'sites and service provision', 'housing policy', 'housing finance', or 'disaster relief'. The revisions were introduced to more explicitly capture the shifting roles of state and market actors within national housing systems. The move from state- to market-based provision is of analytic interest to literatures within Politics and International Studies, and also is a significant factor in the declining level of pro-poor targeting and attendant move from a development agency-like to bank-like approach to housing policy.

25. The Latin American model is focused on, for example, by Ferguson and Navarette (2003), Ferguson (2004), Rojas and Medellín (2011), and Bouillon (2012). There is significant variation across the Latin American region. In relation to the extent of formal provision, for example, the regularised market system generates over 90 per cent of new housing in Chile; in Colombia, the coverage is just 50 per cent. In relation to the availability of decent-quality housing, estimated urban deficits range from just 12 per cent in Costa Rica through to 70 per cent in Nicaragua (Bouillon 2012: 28, 256-257).

26. Works including Mathéy (1990), Struyk (1996), Tsenkova (2008), and Turner et al. (2012) have sought to explore the dynamics associated with post-socialist housing system transformations.

27. See Tipple (1994), Njoh (2003), Gulyani and Bassett (2007), AfDB (2010), UN-Habitat (2011), and Collier and Venables (2014).

28. I follow the lead of Wang (2008) and Zhang (2011) in labelling the Chinese housing system 'post-socialist'. While differing from other cases within the class through the continuation of Communist Party rule, housing system transformations have exhibited a similar trajectory of wholesale privatisation accompanied by efforts to enhanced market-based construction and finance.

29. This study provides an 'organising framework' (Rhodes 1997: 5), presenting a map of the core dynamics and relationships shaping World Bank lending for housing. The work has not been designed to produce generalisable findings regarding the countryspecific factors that facilitate progressivity in national housing systems. Given that a drift toward low levels of pro-poor targeting in World Bank projects is displayed across the three modes of housing system, the work suggests that domestic contexts may have played a limited role in shaping this facet of operational practice. Moves toward more effectively targeted operations are likely to be heavily contingent on the Bank's internal trial-and-error-based learning; the book closes with a review of contemporary dynamics therein. 